
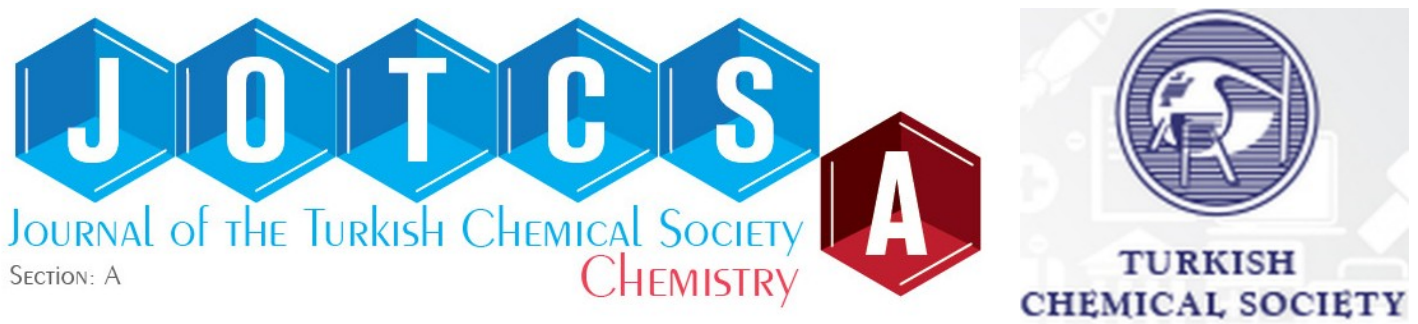

\title{
2-Naphthylthio Cyclotriphosphazene Derivatives: Synthesis, Characterization, Crystallographic and Fluorescence Properties
}

\author{
Ceylan MUTLU BALCI ${ }^{1 *}$ (D)
}

${ }^{1}$ Department of Chemistry, Gebze Technical University, Gebze 41400, Kocaeli, Turkey.

\begin{abstract}
In this study, new cyclotriphosphazene derivatives bearing 2-naphthylthio group were reported. The reactions of hexachlorocyclotriphosphazene (1) with 2-naphthalenethiol (2) were carried out with $\mathrm{NaH}$ base in tetrahydrofuran solution under inert (Ar) atmosphere in (1:2), (1:4) and (1:6) molar ratios. As a result of the reactions, bis geminal (3), tetrakis (4) and hexakis (5) 2-naphthylthio substituted cyclotriphosphazene derivatives formed and isolated. These new compounds were characterized with elemental analysis, mass (MALDI-TOF) analysis, ${ }^{31} \mathrm{P}\{\mathrm{H}\}$ and ${ }^{1} \mathrm{H}$ NMR spectroscopies. The molecular structure of compound $\mathbf{3}$ was illuminated by single-crystal X-Ray diffraction technique. Furthermore, the fluorescence properties of the newly designed and synthesis compounds (3-5) were examined.
\end{abstract}

Keywords: Cyclotriphosphazene, Synthesis, Crystal Structure, Spectroscopy, X-Ray.

Submitted: January 08, 2021. Accepted: March 29, 2021.

Cite this: Mutlu Balcı C. 2-Naphthylthio Cyclotriphosphazene Derivatives: Synthesis, Characterization, Crystallographic and Fluorescence Properties. JOTCSA. 2021;8(2):535-52.

DOI: https://doi.org/10.18596/jotcsa.856600.

*Corresponding author. E-mail: (ceylanmutlu@gtu.edu.tr), Tel: (90 2626053111$),$ Fax: (90 262 6053005).

\section{INTRODUCTION}

Cyclophosphazenes are the most important members of inorganic heterocyclic compounds (19). The most well-known and studied derivatives of cyclophosphazenes are trimer (hexachlorocyclotriphosphazene) and tetramer (octachlorocyclotetraphosphazene). Thanks to their active phosphorus-chlorine bonds, they can be used with many different groups and easily give chlorine displacement reactions (10-16). Another reason these compounds are preferred is to be used as the starting material in the preparation of polyphosphazenes which is the largest class of known inorganic polymers (12). Also, they can be used as ligand in coordination chemistry and organometallic chemistry (10-14). Six-membered trimer $\left(P_{3} N_{3}\right)$ is more preferred and studied than eight-membered tetramer $\left(\mathrm{P}_{4} \mathrm{~N}_{4}\right)$ because it is planar, stable, rigid, and its product range is less than tetramer (17-20). Thus, an easily functionalized platform is created for the preparation of compounds suitable for different and new application areas such as biologically active materials, liquid crystallinity, anticancer agents, fluorescent chemosensors and organic light emitting diodes (21-26).

In order to synthesize materials with intended properties, one must know the reaction mechanism $\left(\mathrm{S}_{N}{ }^{1}\right.$ and $\left.\mathrm{S}_{N}{ }^{2}\right)$ by which nucleophiles proceed. This is very important in controlling the progress of the reaction. For example, some nucleophiles prefer the non-geminal $\left(\mathrm{S}_{N}{ }^{2}\right)$ reaction pathway like alcohols (27-30), while others move through the geminal $\left(\mathrm{S}_{\mathrm{N}}{ }^{1}\right)$ reaction pathway like some primary amines $(31,32)$ and thiol groups $(33,34)$. The replacement of $\mathrm{Cl}$ atoms in $\mathrm{P}-\mathrm{Cl}$ bonds of hexachlorocyclotriphosphazene with thiolate groups follow the geminal $\left(S_{N}{ }^{1}\right)$ reaction mechanism due to 
the low donor ability of the sulfur atom (35). Therefore, geminal product formation is observed $(33,34,36)$. Reactions of cyclotriphosphazenes and thiol group-containing nucleophiles are very rare in the literature (33-37).

Considering the industrial and current uses of luminescent compounds, aromatic groups such as naphthalene are of interest to researchers due to their fluorescence and colorimetric sensor features. Since the cyclotriphosphazene skeleton alone does not show fluorescence-like properties, it can allow the synthesis of molecules with different and tuneable properties depending on the number of substitutions. Nucleophilic substitution studies and fluorescence properties of 2-naphthylamine (38) and 2-naphthol (39) derivatives with hexachlorocyclotriphosphazene have been previously studied. Although 1-naphthylthio cyclotriphosphazene derivatives were seen in the literature (37), there is no report so far about 2naphthylthio cyclotriphosphazene derivatives. In addition, the fluorescence properties of naphthylthio derivatives have not been investigated before.

In this study, nucleophilic substitution reactions of hexachlorocyclotriphosphazene (1) with 2naphthelenethio (2) in 1: 2, 1: 4 and 1: 6 mole ratios were performed in order to determine their product diversity and reaction pathways (Scheme 1). Compounds $\mathbf{3}, \mathbf{4}$ and $\mathbf{5}$ were isolated in pure, and characterized by different characterization methods such as mass analysis and nuclear magnetic resonance spectroscopy. Molecular structure of compound $\mathbf{3}$ was confirmed by X-Ray (single crystal) diffraction technique. And therewithal, fluorescence properties of all these new compounds (3-5) were investigated first time.

\section{EXPERIMENTAL SECTION}

\section{Materials and Instrumentation}

The reagents \{hexachlorocyclotriphosphazene (Aldrich) and 2-naphthalenethiol (Aldrich)\} and solvents \{Dichloromethane, DCM, (Merck), nhexane (Merck), tetrahydrofuran, THF, (Merck)\} which are used for synthesis of compounds 3-5 were purchased commercially. Before using sodium hydride (60\% dispersion in mineral oil, Merck), the oil was removed by washing with dry $n$-hexane. Deuterated chloroform for NMR spectroscopy was also received from Merck commercially. Column chromatography was realized by using Merck, Kieselgel 60, 230-400 mesh silica gel. Again, Merck silica gel plates (Merck, Kieselgel 60, $0.25 \mathrm{~mm}$ thickness) with F254 indicator were used for Thin Layer Chromatography (TLC).

Elementar Vario MICRO Cube was used for elemental analyses. Molecular masses were measured by Bruker Daltonics Microflex MALDI-TOF (Matrix-Assisted Laser Desorption/Ionization-TimeOf-Flight) spectrometer and 1,8,9trihydroxyanthracene was used as a matrix. ${ }^{1} \mathrm{H}$ and ${ }^{31} \mathrm{P}$ NMR spectra were analyzed for all compounds in $\mathrm{CDCl}_{3}$ on a Varian INOVA $500 \mathrm{MHz}$ spectrometer. Melting point analyses were performed by Stuart SMP3 melting point apparatus. Varian Eclipse spectrofluorometer and Shimadzu 2101 UV spectrophotometer were used for recording fluorescent and the electronic absorption spectra of compounds 3-5 in the UV-Vis region. Measurements were taken at $25^{\circ} \mathrm{C}$ using $1 \mathrm{~cm}$-wide quartz cuvettes.

Single crystals were obtained at ambient temperature. Appropriate single crystals of compounds $\mathbf{3}$ and $\mathbf{5}$ were selected under a polarized microscope. Then it was cleaned in perfluoro polyether oil and taken to the goniometer to be attached to the single crystal X-Ray diffraction device. Although the data of both compounds were collected, only the data of compound $\mathbf{3}$ could be refined. Data were obtained with a Bruker APEX II QUAZAR three-circle diffractometer using monochromatized Molybdenum X-radiation ( $\lambda=0.71073$ $\AA$ ). Absorption correction was performed by the multi-scan method implemented in SADABS (40) and space groups were assigned using XPREP implemented in APEXII (41). Structures were identified using the direct methods procedure in SHELXS-97 and refined by full-matrix least squares on $\mathrm{F}^{2}$ using SHELXL-97 (42). Aromatic C-bound $\mathrm{H}$ atoms were positioned geometrically and refined using a riding mode. Crystal structure validations and geometrical calculations were performed using PLATON software (43). MERCURY software (44) was used for visualization of the cif file. The DIAMOND (45) program was used for molecular drawing. Crystallographic data with Cambridge Crystallographic Data Centre reference number 2052687 for compound $\mathbf{3}$ has been deposited.

\section{Synthesis of the compounds 3, 4 and 5}

Reaction of hexachlorocyclotriphosphazene (1) with 2-naphthalenethiol (2) at a 1:2 molar ratio Hexachlorocyclotriphosphazene $\left[\mathrm{P}_{3} \mathrm{~N}_{3} \mathrm{Cl}_{6}\right] \mathbf{1},(1.74 \mathrm{~g}$, $5 \mathrm{mmol}$ ) was dissolved in $80 \mathrm{~mL}$ of THF in a $250 \mathrm{~mL}$ three-necked reaction flask. 2-Naphthalenethiol $(1.60 \mathrm{~g}, 10 \mathrm{mmol})$ in $20 \mathrm{~mL}$ of dry THF was added into the stirred solution. Then, the reaction mixture was cooled on an ice bath and $\mathrm{NaH}(60 \%$ oil suspension, $0.4 \mathrm{~g}, 10 \mathrm{mmol}$ ) in $20 \mathrm{~mL}$ of dry THF was quickly added under an inert (Ar) atmosphere. The reaction was continued during a day at ambient temperature. At the end of the reaction, one new product was observed by using TLC solvent system, $n$-hexane-THF (30:1). The crude product was subjected to column chromatography using same 
solvent system. Bis geminal naphthylthio compound 3 was eluted from the column. The colorless crystals were obtained from $n$-hexane:DCM (3:1) system.

Anal Calc. for 3; $\mathrm{C}_{20} \mathrm{H}_{14} \mathrm{Cl}_{4} \mathrm{~N}_{3} \mathrm{P}_{3} \mathrm{~S}_{2}: 40.36$ (C); 2.37 $(\mathrm{H}) ; 7.06(\mathrm{~N}) \%, \mathrm{M}, 595.2 \mathrm{~m} / \mathrm{z}$.

Compound 3 (2.44 g, yield: $82 \%$, m.p. $\left.167{ }^{\circ} \mathrm{C}\right)$, Found \%: $40.66(\mathrm{C}), 2.59(\mathrm{H}), 6.98(\mathrm{~N}),[\mathrm{M}]^{+}$: $595.7 \mathrm{~m} / \mathrm{z}$ (Figure S1). ${ }^{1} \mathrm{H} \mathrm{NMR}$, in $\mathrm{CDCl}_{3}$ at $25{ }^{\circ} \mathrm{C}$, ठppm; 8.17-7.54 ppm (m, 14H, Ar-H). ${ }^{31} \mathrm{P}$ $\mathrm{NMR}\left\{{ }^{1} \mathrm{H}\right\}, \mathrm{CDCl}_{3}, 25{ }^{\circ} \mathrm{C}, \mathrm{AX}_{2}$ spin system, $\delta(\mathrm{ppm})$; $11.8\left(\mathrm{~d}, 2 \times \mathrm{PCl}_{2},{ }^{2} \mathrm{~J}=8.30 \mathrm{~Hz}\right)$ and $47.8[\mathrm{t}$, $\left.\mathrm{P}\left(\mathrm{SC}_{10} \mathrm{H}_{7}\right)_{2},{ }^{2} \mathrm{~J}_{\mathrm{AX}}=8.30 \mathrm{~Hz}\right]$.

Reaction of hexachlorocyclotriphosphazene (1) with 2-naphthalenethiol (2) at a 1:4 molar ratio

The general reaction medium and procedure is the same as in the previous experimental part. In here, hexachlorocyclotriphosphazene $\left[\mathrm{P}_{3} \mathrm{~N}_{3} \mathrm{Cl}_{6}\right] \mathbf{1},(1.74 \mathrm{~g}$, $5 \mathrm{mmol}), 2$-naphthalenethiol $(3.21 \mathrm{~g}, 20 \mathrm{mmol})$ and $\mathrm{NaH}(60 \%$ oil suspension, $0.8 \mathrm{~g}, 20 \mathrm{mmol})$ were used. Products were purified again by column chromatography using $n$-hexane-THF (10:1) solvent system. Firstly, bis geminal naphthylthio compound $3(0.65 \mathrm{~g}, 21 \%)$ was eluted from the column and secondly, tetrakis naphthylthio substituted compound 4 was isolated as a white solid. Although many solvent systems and crystallization techniques were tried, suitable single crystals could not be obtained.

Anal Calc. for 4; $\mathrm{C}_{40} \mathrm{H}_{28} \mathrm{Cl}_{2} \mathrm{~N}_{3} \mathrm{P}_{3} \mathrm{~S}_{4}$ : C, 57.01; $\mathrm{H}, 3.35$; $\mathrm{N}, 4.99 \%, \mathrm{M}, 842.7 \mathrm{~m} / \mathrm{z}$.
Compound 4 (2.78 g, yield: $65 \%$, m.p. $\left.156{ }^{\circ} \mathrm{C}\right)$, Found: $\mathrm{C}, 57.41 ; \mathrm{H}, 3.59 ; \mathrm{N}, 4.68 \%,[\mathrm{M}]^{+}, 842.1$ $\mathrm{m} / \mathrm{z}$ (Figure S2). ${ }^{1} \mathrm{H} \mathrm{NMR}$, in $\mathrm{CDCl}_{3}$ at $25^{\circ} \mathrm{C}, \delta p p m$; 7.99-7.49 ppm (m, 28H, Ar-H). ${ }^{31} \mathrm{P} N M R\left\{{ }^{1} \mathrm{H}\right\}$, $\mathrm{CDCl}_{3}, 25{ }^{\circ} \mathrm{C}, \mathrm{A}_{2} \mathrm{X}$ spin system, $\delta(\mathrm{ppm}) ; 17.9$ [s, $\left.\mathrm{PCl}_{2}\right]$ and $45.6\left[\mathrm{~s}, 2 \times \mathrm{P}\left(\mathrm{SC}_{10} \mathrm{H}_{7}\right)_{2}\right]$.

Reaction of hexachlorocyclotriphosphazene (1) with 2-naphthalenethiol (2) at a 1:6 molar ratio

The general reaction medium and procedure is the same as in the previous experimental parts. In here hexachlorocyclotriphosphazene $\left[\mathrm{P}_{3} \mathrm{~N}_{3} \mathrm{Cl}_{6}\right] \mathbf{1},(0.44 \mathrm{~g}$, $1.25 \mathrm{mmol}), 2$-naphthalenethiol $(1.20 \mathrm{~g}, 7.5 \mathrm{mmol})$ and $\mathrm{NaH}$ ( $60 \%$ oil suspension, $0.3 \mathrm{~g}, 7.5 \mathrm{mmol}$ ) were used. Column chromatography solvent system is $n$-hexane-THF (4:1). Firstly, tetrakis naphthylthio compound $4(0.29 \mathrm{~g}, 45 \%)$ was eluted from the column and secondly, hexakis naphthylthio (full) substituted compound $\mathbf{5}$ was isolated as a white solid. Compound $\mathbf{5}$ was re-crystallized from $n$ heptane:DCM (3:1) and obtained as colorless very weak, thin and plate crystals.

Anal Calc. for 5; $\mathrm{C}_{60} \mathrm{H}_{42} \mathrm{~N}_{3} \mathrm{P}_{3} \mathrm{~S}_{6}: 66.10$ (C); $3.88(\mathrm{H})$; $3.85(\mathrm{~N}) \%, \mathrm{M}, 1090.3 \mathrm{~m} / \mathrm{z}$.

Compound $5\left(0.14\right.$ g, yield: $10 \%$, m.p. $\left.212{ }^{\circ} \mathrm{C}\right)$, Found: $\mathrm{C}, 57.41 ; \mathrm{H}, 3.59 ; \mathrm{N}, 4.68 \%,[\mathrm{M}+\mathrm{H}]^{+}$, $1091.8 \mathrm{~m} / \mathrm{z}$ (Figure S3). ${ }^{1} \mathrm{H} \mathrm{NMR}$, in $\mathrm{CDCl}_{3}$ at $25{ }^{\circ} \mathrm{C}$, סppm; 7.80-7.28 ppm (m, 42H, Ar-H) ${ }^{31} \mathrm{P} N M R\left\{{ }^{1} \mathrm{H}\right\}$, $\mathrm{CDCl}_{3}, 25{ }^{\circ} \mathrm{C}, \mathrm{A}_{3}$ spin system, $\delta(\mathrm{ppm}) ; 43.3[\mathrm{~s}$, $\left.3 \times P\left(\mathrm{SC}_{10} \mathrm{H}_{7}\right)_{2}\right]$.

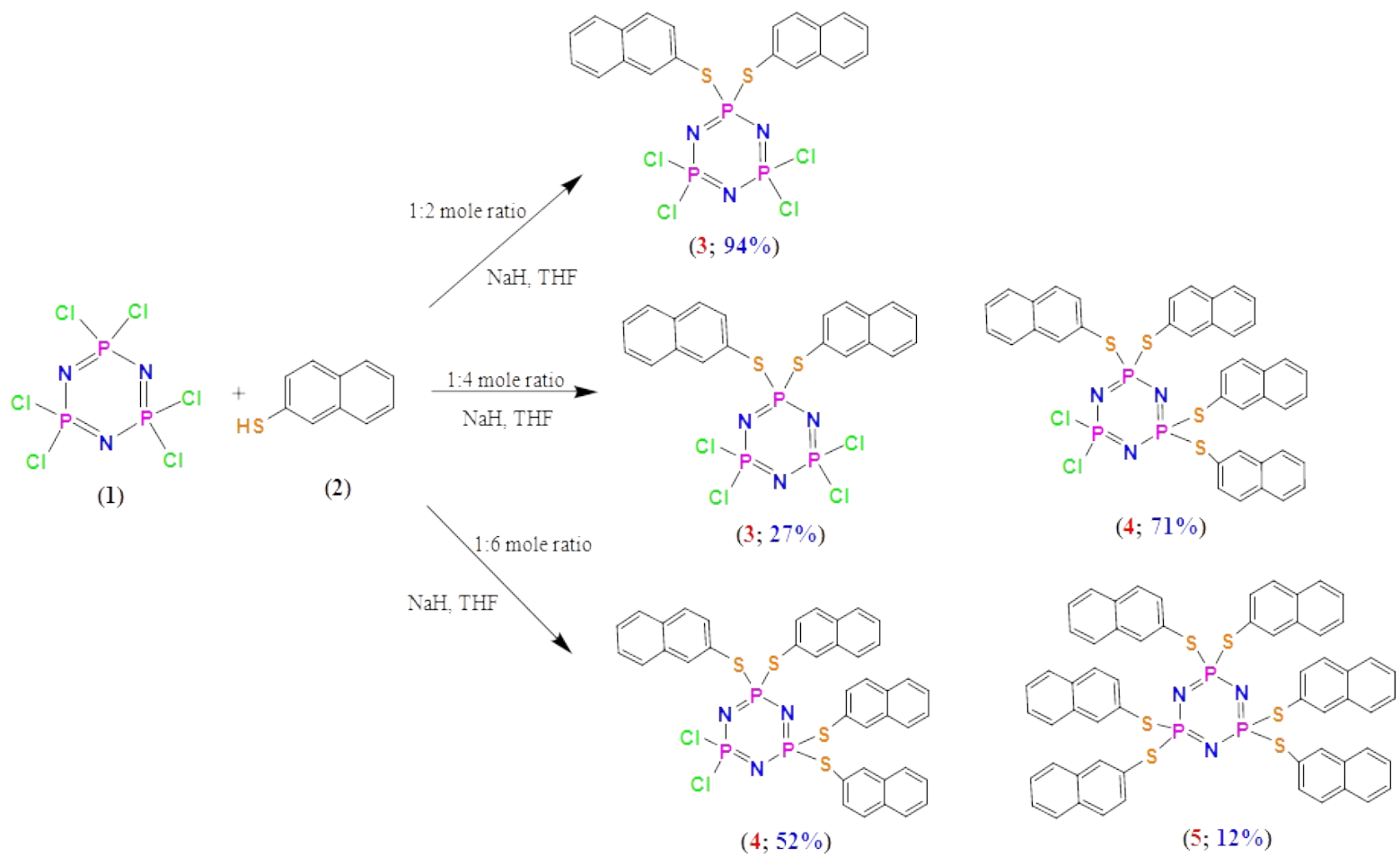

Scheme 1: The synthesis and relative amounts of compounds 3, 4 and $\mathbf{5}$. 


\section{RESULTS AND DISCUSSION}

\section{Structural Characterization}

The reactions of hexachlorocyclotriphosphazene and 2-naphthalenethiol were performed under inert (Ar) atmosphere using THF solvent in the presence of $\mathrm{NaH}$ base. Reactions at three different molar ratios (1: 2, 1: 4 and 1:6) were performed to determine the variety of products. As a result of the reactions; geminal bis (3), tetrakis (4) and hexakis (5) naphthylthio substituted cyclotriphosphazene derivatives were isolated. Formation and diversity of product quantities were determined by detailed examination of ${ }^{31} \mathrm{P}\{\mathrm{H}\}$ NMR of the reaction mixture. The structures of cyclotriphosphazene derivatives were confirmed by elemental analysis, mass spectroscopy (MALDI-TOF), ${ }^{1} \mathrm{H}$ and ${ }^{31} \mathrm{P}$ NMR spectroscopies. The elemental analyses, mass analysis results and the phosphorus chemical shifts of each new compound are given in the experimental section.

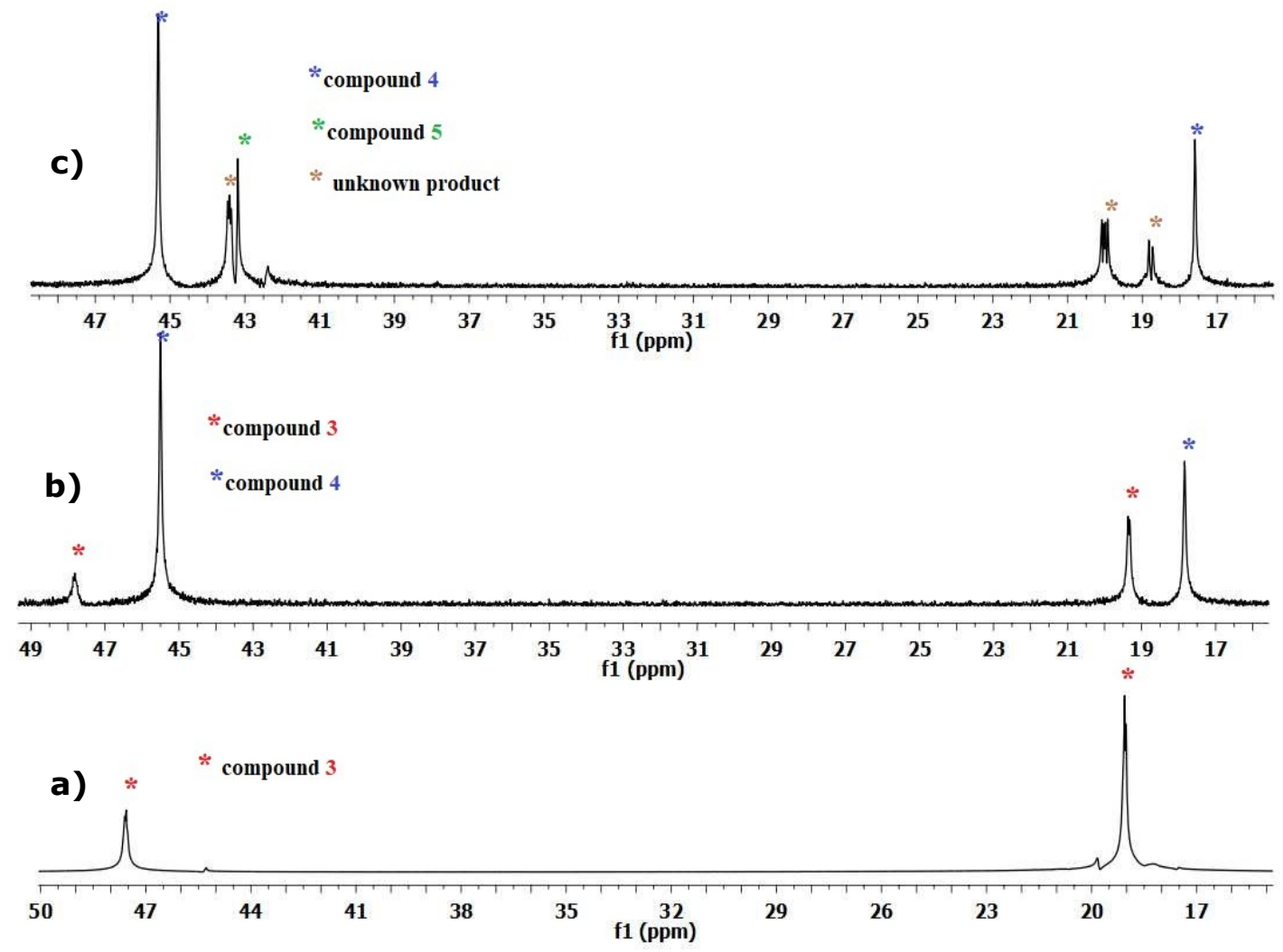

Figure 1. Proton-decoupled ${ }^{31} \mathrm{P}$ NMR spectra of the product of reaction of compound $\mathbf{1}$ with $\mathbf{2}$ a) $1: 2$ molar ratio b) 1:4 molar ratio and c) 1:6 molar ratio, in THF solution; the reaction mixture was filtered, and the solvent removed prior to dissolving in $\mathrm{CDCl}_{3}$ solution.

The examination of the ${ }^{31} \mathrm{P}\{\mathrm{H}\}$ NMR of the reaction mixture allowed for the assignment of the relative amounts of each compound. The proton decoupled ${ }^{31} \mathrm{P}$ NMR spectrum of the reaction mixture, which was carried out at a 1: 2 mole ratio, was examined (Figure 1a), it was observed that the one major product (3), which had $\mathrm{AX}_{2}$ spin system, with $94 \%$ yield was formed. At the same time, a product thought to be a trace amount of tetrakis compound was seen in ${ }^{31} \mathrm{P}\{\mathrm{H}\} \mathrm{NMR}$ of the reaction mixture. After purification, when evaluating the mass and elemental analysis of compound 3, it was determined two naphthylthio groups were attached to the cyclotriphosphazene ring. It actually reveals the geminal or non-geminal bonding possibilities of naphthylthio groups to cyclotriphosphazene core. It is known that the phosphorus atom in thiol group substituted cyclotriphosphazene derivatives shifts to high frequency (downfield) about between 43.0 and $48.0 \mathrm{ppm}(32,37)$. Therefore, it was determined that the group resonating at $48.0 \mathrm{ppm}$ (the integral value of the $P$ atom is one) is naphthylthio substituted phosphorus atom, and the group resonating around 12.0 (the integral value of the $P$ atom is two) ppm belongs to the $\mathrm{PCl}_{2}$ group. When the spectrum as a whole is evaluated, it is determined that structure is bis-geminal. It is seen $\left[\mathrm{P}\left(\mathrm{SC}_{10} \mathrm{H}_{7}\right)_{2}\right]$ group is split into three due to two $\mathrm{PCl}_{2}$ groups having the same chemical environment, and double splitting of $\mathrm{PCl}_{2}$ groups were assigned because of phosphorus atom with naphthylthio group (Figure 2a). Therefore, it is understood from 
this point that it follows the $S_{N}{ }^{1}$ reaction mechanism as expected. Also, the molecular structure of the bis geminal compound $\mathbf{3}$ has been confirmed by single crystal X-Ray diffraction.

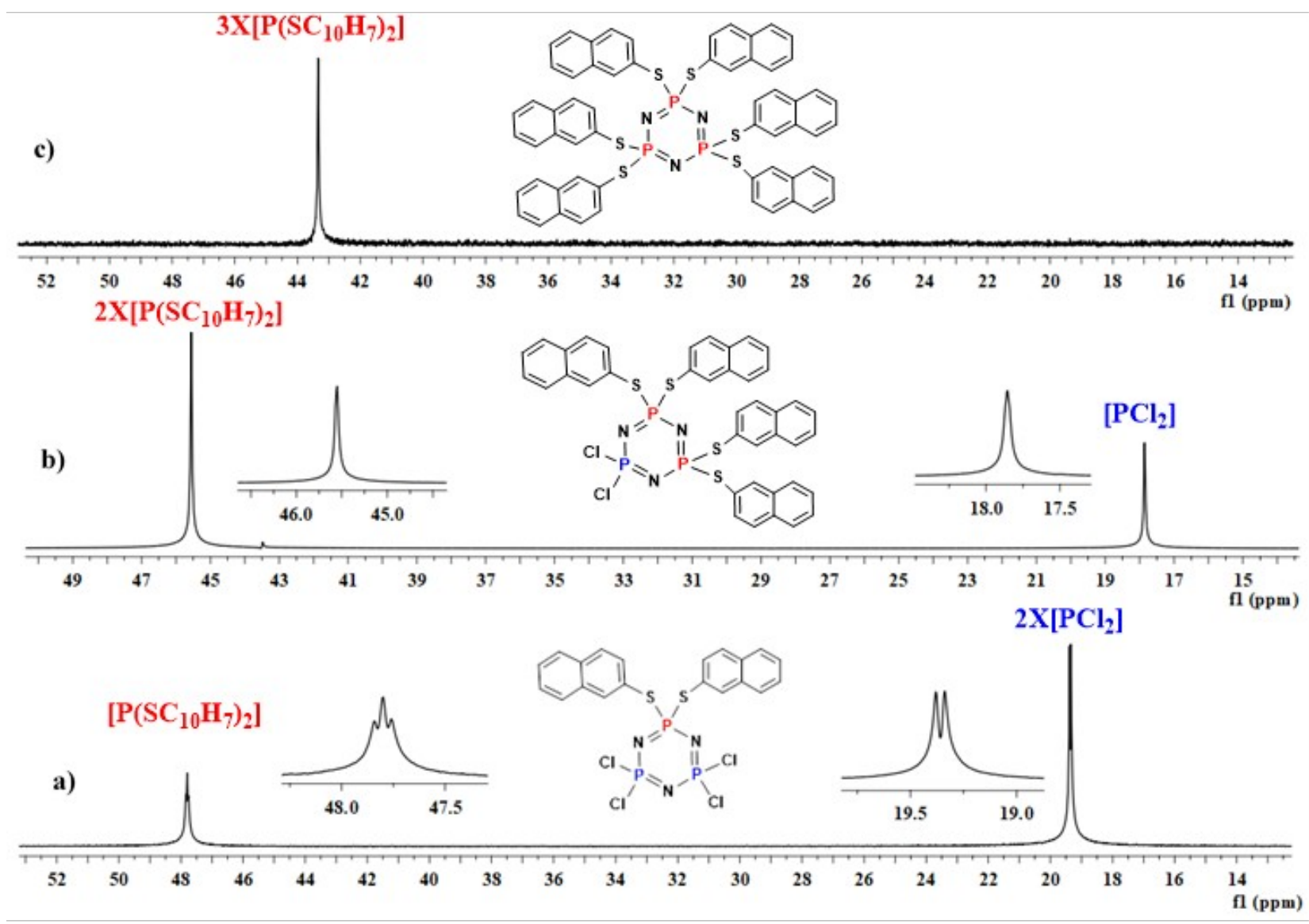

Figure 2. Proton-decoupled ${ }^{31}$ P NMR spectra of the a) compound $\mathbf{3}$ and b) compound $\mathbf{4}$ c) compound $\mathbf{5}$.

When the ${ }^{31} \mathrm{P}$ NMR spectrum of the reaction mixture was examined at 1: 4 molar ratios, it was seen that two products with spin system $\mathrm{AX}_{2}(27 \%)$, belongs to compound 3, and $\mathrm{A}_{2} \mathrm{X}(71 \%)$ were formed (Figure $1 b)$. When the integral values and locations of the peak groups belonging to the $A_{2} X$ system were evaluated, it was thought that the structure could be a geminal tetrakis product (4). Mass and elemental analyses also confirm this situation. In the ${ }^{31} \mathrm{P}$ NMR spectrum of compound 4, the peaks of the $\mathrm{PCl}_{2}$ group and the $\left[\mathrm{P}\left(\mathrm{SC}_{10} \mathrm{H}_{7}\right)_{2}\right]$ group are not split and they are in single peak form (Figure $2 b$ ) (32). The Gaussian of the spectrum has been carefully studied. It was observed that the groups
$\left[\mathrm{P}\left(\mathrm{SC}_{10} \mathrm{H}_{7}\right)_{2}\right]$ and $\left[\mathrm{PCl}_{2}\right]$ did not split again. When ${ }^{31} \mathrm{P}\{1 \mathrm{H}\}$ NMR spectrum was taken in other $\mathrm{d}$-solvent (toluene-d8) may be peak splitting in this group can be observed (32).

When the reaction was carried out at a ratio of $1: 6$ moles, it was observed that in ${ }^{31} \mathrm{P}\{\mathrm{H}\} \mathrm{NMR}$ of the reaction mixture, $12 \%$ of the hexakis (full) substituted product (5) (Figure 1c), which had $A_{3}$ spin system (due to the chemical equivalent phosphorus atoms) shown in Figure 2c, 52\% of geminal tetrakis product (4), which had $A_{2} X$ spin system, and $36 \%$ of unknown products formed in the reaction mixture (Figure $1 \mathrm{c}$ ). 


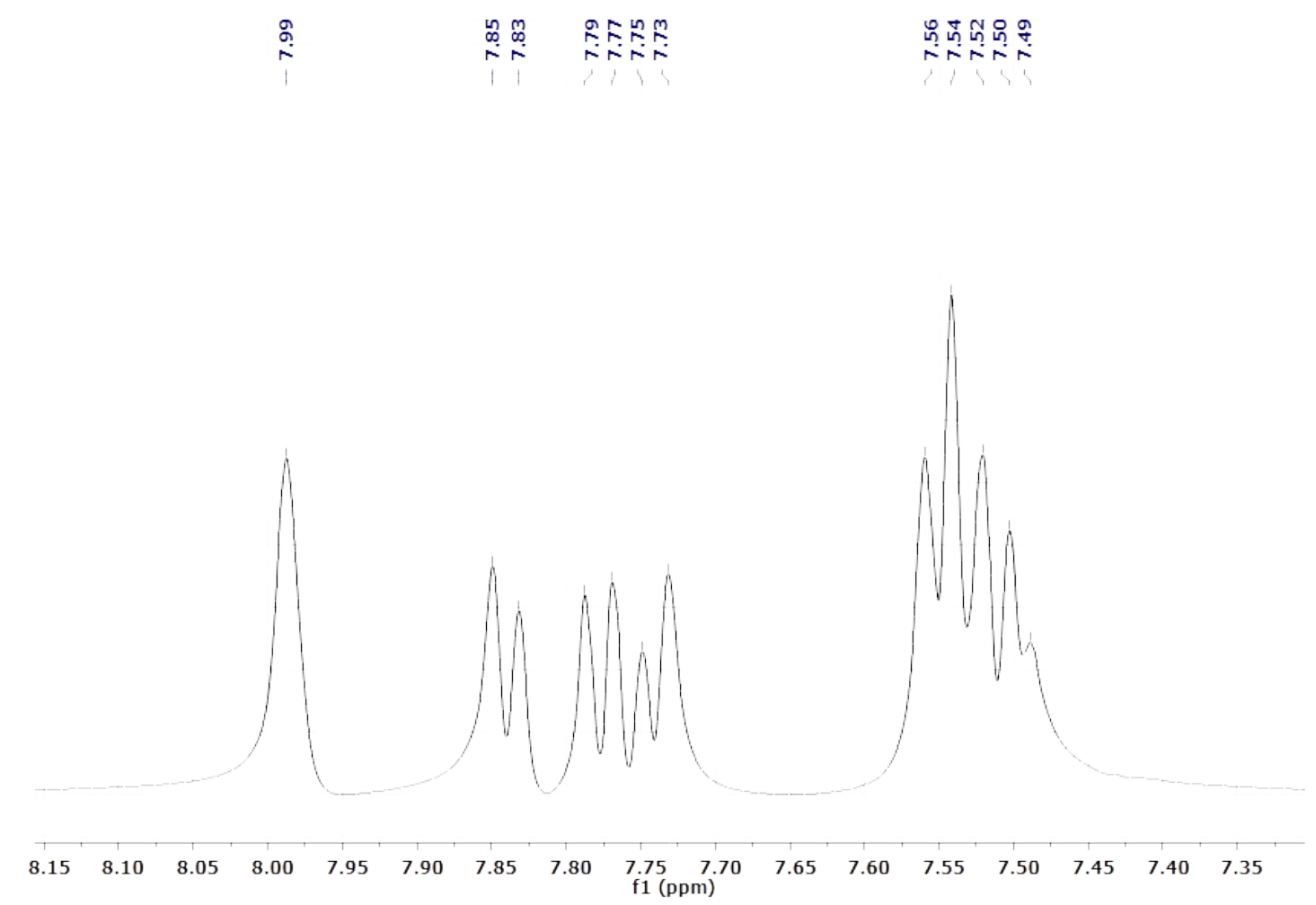

Figure 3. ${ }^{1} \mathrm{H}$ NMR spectrum of the compound 4.

The ${ }^{1} \mathrm{H}$ NMR spectra of all three compounds (3-5) are very similar. Aromatic protons in naphthyl groups resonate in the range 7.28-8.17 ppm. Since the protons in the synthesized compounds are all aromatic protons, the spectra are quite similar to each other. Therefore, only the ${ }^{1} \mathrm{H}$ NMR spectrum of compound 4 is given as an example (Figure 3 ). ${ }^{1} \mathrm{H}$ NMR spectra of compounds $\mathbf{3}$ and $\mathbf{5}$ were also given supplementary material (Figure S4 and S5).

\section{X-Ray Structure Analysis for Compound 3}

The crystal structure of $\mathbf{3}$ was illuminated by single crystal X-Ray diffraction. The molecular structure of 3 along with the atom-numbering scheme is shown in Figure 4. The crystal structure of compound $\mathbf{5}$ was also approved by single crystal X-ray diffraction. But the crystal structure could not be fully elucidated due to crystallographic problems. Although different crystallization systems and methods were tried, suitable crystals could not be obtained. The X-Ray crystallographic data collection and refinement parameters for compound $\mathbf{3}$ are summarized in Table 1.

The crystal structure of compound $\mathbf{3}$ showed that it contains a 6-membered cyclotriphosphazene $\left(\mathrm{P}_{3} \mathrm{~N}_{3}\right)$ ring, substituted with two 2-naphtalenethio groups on the same phosphorus atom (P1) (Figure 4). Compound $\mathbf{3}$ has orthorhombic system, space group Pccn, and molecule sits on inversion centre [symmetry code (\#): 1/2-x,3/2-y, z] (Table 1).

Table 1. X-ray crystallographic parameters for compound 3.

\begin{tabular}{l} 
Compound \\
\hline Empirical formula \\
Formula weight $(\mathrm{g} / \mathrm{mol})$ \\
Temperature $(\mathrm{K})$ \\
Crystal system \\
Space group \\
$\mathrm{a}(\AA)$ \\
$\mathrm{b}(\AA)$ \\
$\mathrm{c}(\AA)$ \\
$\mathrm{a}\left({ }^{\circ}\right)$ \\
$\beta\left(^{\circ}\right)$
\end{tabular}

$\mathrm{C}_{20} \mathrm{H}_{14} \mathrm{Cl}_{4} \mathrm{~N}_{3} \mathrm{P}_{3} \mathrm{~S}_{2}$

595.17

296(2)

orthorhombic

P c c n

6.9214(5)

13.6686(8)

26.4880(16)

90

90 


\begin{tabular}{|c|c|}
\hline $\mathbf{Y}\left({ }^{\circ}\right)$ & 90 \\
\hline Volume $\left(\AA^{3}\right)$ & $2505.9(3)$ \\
\hline $\mathbf{Z}$ & 4 \\
\hline Density (calc, $\mathbf{M g} / \mathbf{m}^{3}$ ) & 1.578 \\
\hline Absorption Coefficient $\left(\mathrm{mm}^{-1}\right)$ & 0.847 \\
\hline$F(000)$ & 1200 \\
\hline Crystal size $\left(\mathrm{mm}^{3}\right)$ & $0.18 \times 0.20 \times 0.31$ \\
\hline$\theta \max \left({ }^{\circ}\right)$ & 25.00 \\
\hline Reflections collected & 32937 \\
\hline Independent reflections & 2207 \\
\hline $\mathbf{R}_{\text {int }}$ (merging R value) & 0.0351 \\
\hline Parameter & 146 \\
\hline$R\left(F^{2}>2 \Theta F^{2}\right)$ & 0.0377 \\
\hline wR (all data) & 0.1046 \\
\hline Goodness-of-fit on $F^{2}$ & 1.057 \\
\hline$\Theta X \max / \min \left(e \AA^{-3}\right)$ & 0.574 and -0.476 \\
\hline
\end{tabular}

Table 2. Some bond and conformational parameters of compound $\mathbf{3}$

\begin{tabular}{|c|c|c|c|}
\hline & 3 & & 3 \\
\hline P1-N1 & $1.600(2)$ & N1-P2-N2 & $119.52(13)$ \\
\hline N1-P2 & $1.557(2)$ & P1-N1-P2 & $122.31(14)$ \\
\hline P2-N2 & $1.5771(17)$ & N1-P1-N1 & $116.06(16)$ \\
\hline P1-S1 & $2.0574(8)$ & P2-N2-P2 & $120.2(2)$ \\
\hline P2-Cl1 & $1.9794(13)$ & N1-P1-S1 & $101.26(9)$ \\
\hline P2-Cl2 & $1.9977(12)$ & N1-P1-S1 & $114.19(10)$ \\
\hline S1-C1 & $1.778(2)$ & N2-P2-Cl1 & $108.52(8)$ \\
\hline P1-N1-P2-N2 & $3.4(2)$ & N2-P2-Cl2 & $108.21(7)$ \\
\hline N1-P2-N2-P2 & $-1.66(12)$ & C1-S1-P1 & $103.59(8)$ \\
\hline P2-N1-P1-N1 & $-1.72(13)$ & S1-P1-S1 & $110.33(5)$ \\
\hline Cl2-P2-N1-P1 & $-121.55(17)$ & Cl1-P2-N1-P1 & $129.62(16)$ \\
\hline S1-P1-N1-P2 & $-118.97(17)$ & S1-P1-N1-P2 & $122.50(18)$ \\
\hline Cl2-P2-N2-P2 & $123.58(6)$ & Cl1-P2-N2-P2 & $-128.46(7)$ \\
\hline P1-S1-C1-C2 & $61.1(2)$ & P1-S1-C1-C10 & $-124.00(18)$ \\
\hline $\begin{array}{l}\text { Max. Deviation } \\
\text { for } \mathrm{P}_{3} \mathrm{~N}_{3} \text { ring }\end{array}$ & $-0.020(2)(N 1)$ & $\begin{array}{l}\text { Puckering } \\
\text { amplitude, } Q \text { for } \\
P_{3} N_{3}\end{array}$ & Planar \\
\hline
\end{tabular}

There have been some changes in $\mathrm{P}-\mathrm{N}$ bond lengths and $\mathrm{P}-\mathrm{N}-\mathrm{P}$ bond angles as a result of the replacement of 2-naphthylthio groups with $\mathrm{Cl}$ atoms. The P1-N1 bond length $[1.600$ (2) $\AA]$ is slightly greater than the bond length of P2-N2 [1.5771 (17) $\AA$ ] (Table 2). Also, the P1-S1 bond length $[2.0574(8) \AA]$ is slightly greater than the $\mathrm{P}-\mathrm{Cl}$ bond lengths [av.1.9885 $\AA$ ]. When the N-P-N angles were examined, it was determined that the N1-P1$\mathrm{N} 1$ bond angle [116.06 (16) $\AA$ ] containing the P1 phosphorus atom (naphthylthio group substituted) was smaller than the N1-P2-N2 bond angle [119.52 (13) $\AA$ ] (Table 2). In compound 3, 6-membered cyclophosphazene ring is planar and the max. deviations from the main plane is $-0.020(2)$ (N1) (Table 2). The found values are similar and compatible with the bis geminal 1-naphthylthio substituted cyclotriphosphazene compound (37), as well as with other substituted cyclotriphosphazene compounds (46-49). The crystal structures of bis geminal 1-naphthalenethio cyclotriphosphazene compound, which was previously synthesized (37), and the compound $\mathbf{3}$ which was synthesized in this study were compared. Crystal structures of bis geminal 1- and 2-naphthylamino cyclotriphosphazenes $(37,38)$ were also examined in CCDC (Cambridge Crystallographic Data Centre) in order to investigate this difference, but it was seen that there was not such a big difference as in thiol groups. Interestingly, it was observed that the naphthylthio groups in these two isomers crystallized at very different positions (Figure 5). 


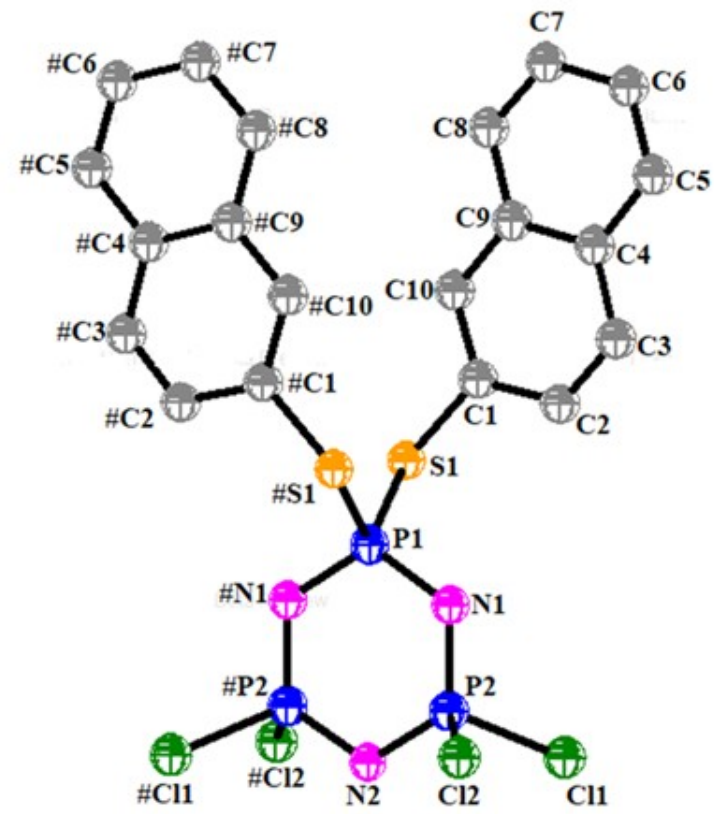

Figure 4. Molecular structure of compound $\mathbf{3}$ (ellipsoids were drawn $50 \%$ probability level). All hydrogen atoms were omitted for clarity.

In the 1-naphthylthio group substituted cyclotriphosphazene compound, the distance between S-S was $3.150 \AA$, while this value was $3.377 \AA$ in the 2-naphthylthio substituted cyclotriphosphazene (3). Also, the S-P-S angle of compound $\mathbf{3}\left(110.33^{\circ}\right)$ is also greater than the S-P$\mathrm{S}\left(98.45^{\circ}\right)$ in the 1 -naphthylthio isomer (Figure 5). The different position of the naphthyl groups naturally resulted in the differences between intra and inter molecular interactions. While in 1naphthylthio cyclotriphosphazene compound, the $\mathrm{N}$ atom and $\mathrm{Cl}$ atom in the $\mathrm{P}_{3} \mathrm{~N}_{3}$ ring play a role in intermolecular interactions (Figure 6a), in compound 3 , the $\mathrm{C}, \mathrm{H}$ and $\mathrm{S}$ groups on the naphthyl groups are predominantly involved in the interactions (Figure 6b). Crystal-packing give very important and valuable information about the arrangement of the molecules in the crystal. Therefore, in order to investigate the contributions of the interactions of aromatic rings on cyclotriphosphazene ring, crystal packing of compound $\mathbf{3}$ was examined. The packing of both isomers along the $b$ axis is shown in Figure 6. Compound $\mathbf{3}$ has $\Pi-\pi$ interactions (Figure $6 \mathrm{c}$ ) in the crystalline structure ranging from 3.6725 (15) $\AA$ ( $\mathrm{Cg} 2-\mathrm{Cg} 2 ; \mathrm{Cg} 2$ is the centroids of the $\mathrm{C} 4-\mathrm{C} 9$ ring) to 5.8031 (14) $\AA$ ( $\mathrm{Cg} 2-\mathrm{Cg} 4 ; \mathrm{Cg} 2$ and $\mathrm{Cg} 4$ are the centroids of the $\mathrm{C} 4-\mathrm{C} 9$ and $\mathrm{C} 1-\mathrm{C} 10$ rings, respectively). 


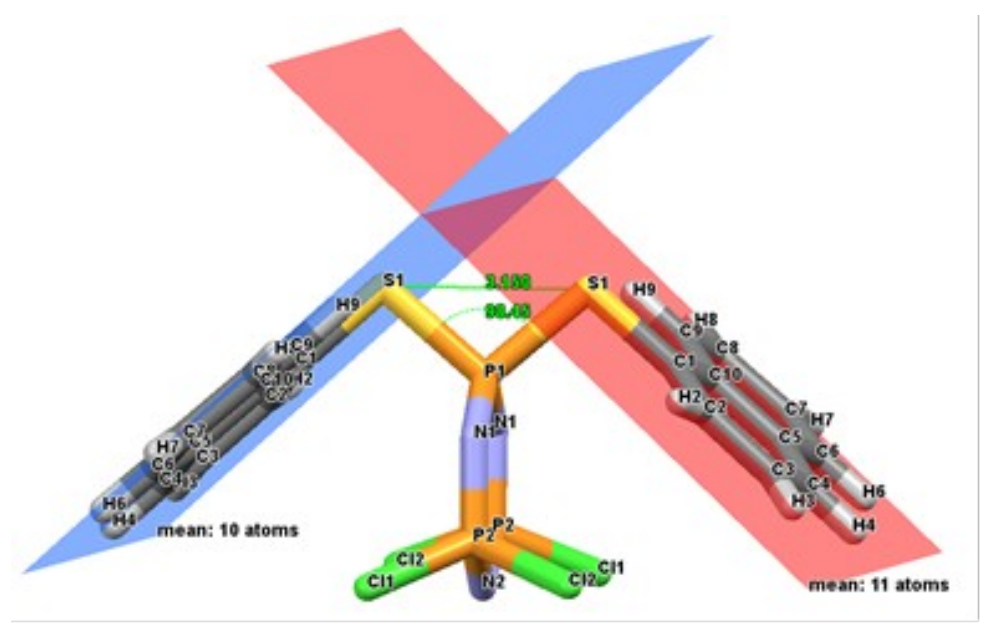

a)

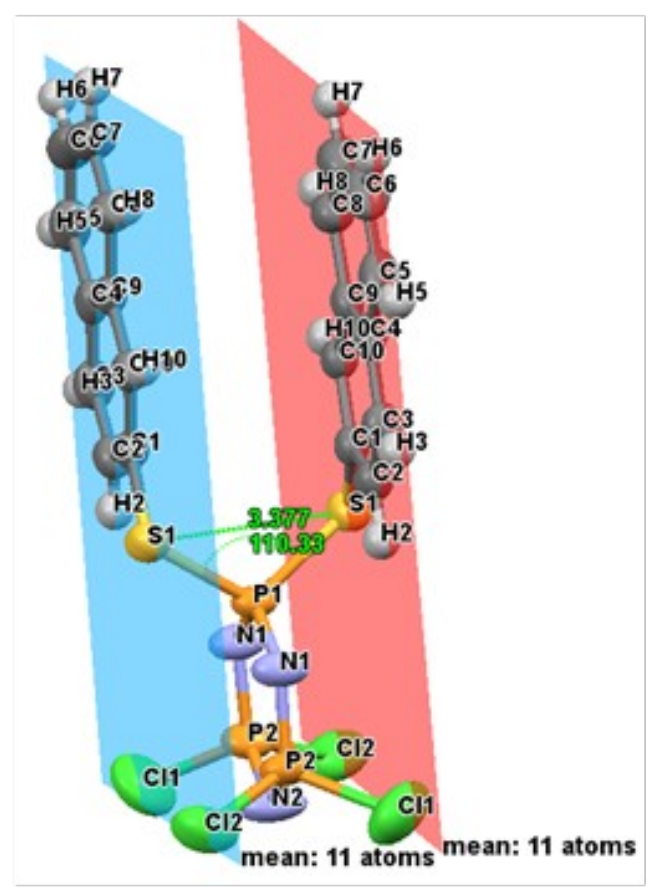

b)

Figure 5. Position of naphthylthio groups on main plane and representation of P-S and S-S distances a) 1naphthylthio groups (37) b) 2- naphthylthio groups. 


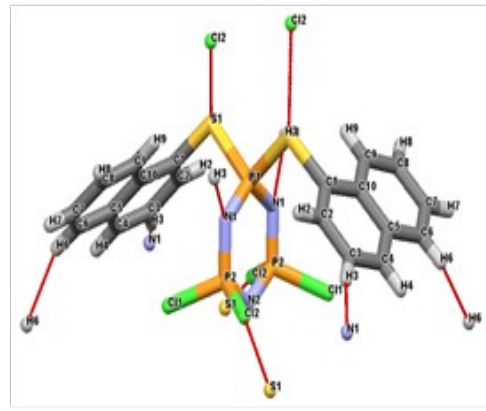

a)

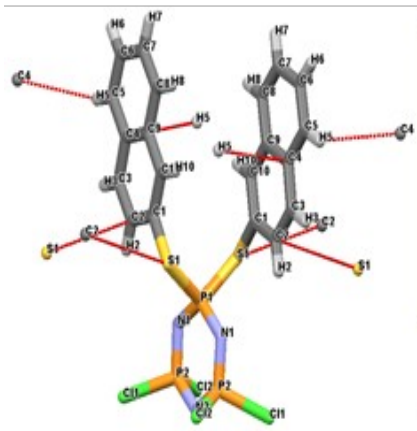

b)
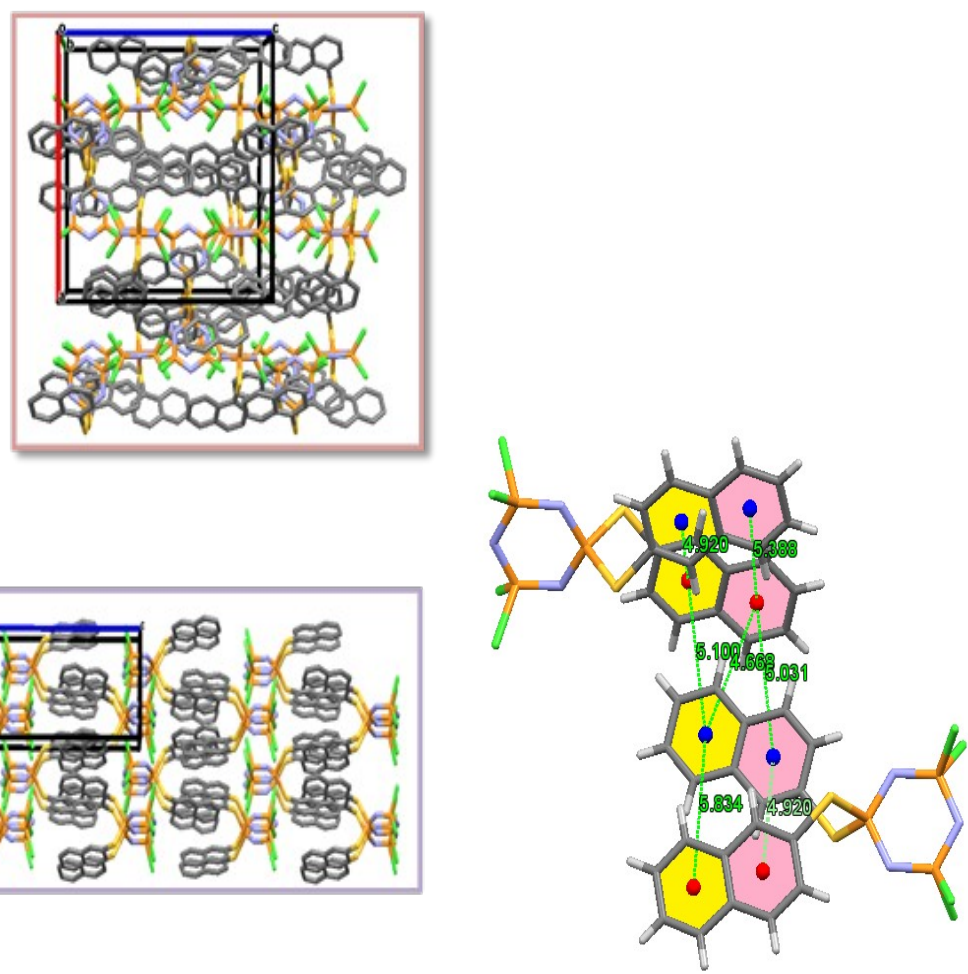

C)

Figure 6: Representation of inter molecular interactions and the arrangement / packaging of molecules along the $b$ axis a) bis geminal 1-naphthylthio (38) b) bis geminal 2-naphthylthio cyclotriphosphazene (3) c) $\Pi-\pi$ interactions in compound 3

\section{Fluorescence Properties}

The hexachlorocyclotriphosphazene can be used as a suitable scaffold for optical materials because the six membered $(\mathrm{PN})_{3}$ skeleton does not have any absorption or emission properties in UV-Vis region (46). In this work, after structural characterization of 3, 4 and 5, it was examined the absorption and emission properties of 2-naphthalenethiolsubstituted cyclotriphosphazene derivatives in solution state by UV-Vis absorption and florescence emission experiments.

Fluorescence studies of naphthol and naphthylamine substituted cyclotriphosphazene $(38,39)$ compounds have been previously conducted in the literature.
However, there is no information about on fluorescence studies of naphthylthio cyclotriphosphazene derivatives. Electronic absorbance and fluorescence measurements of these new compounds (3-5) were carried out under three different concentrations $\left(1 \times 10^{-6} \mathrm{M}, 5 \times 10^{-6} \mathrm{M}\right.$ and $1 \times 10^{-5} \mathrm{M}$ ) in tetrahydrofuran (THF). UV absorption bands in compound 3-5 were observed in the range of $270-280 \mathrm{~nm}$, except for small changes in peak intensities. Fluorescence emission peaks were observed around $310 \mathrm{~nm}$. It was determined that the fluorescence intensity was approximately the same in the three compounds at $1 \times 10^{-6} \mathrm{M}$ and $5 \times 10^{-6} \mathrm{M}$ THF. Fluorescence emission spectra are given in Figure 7. 


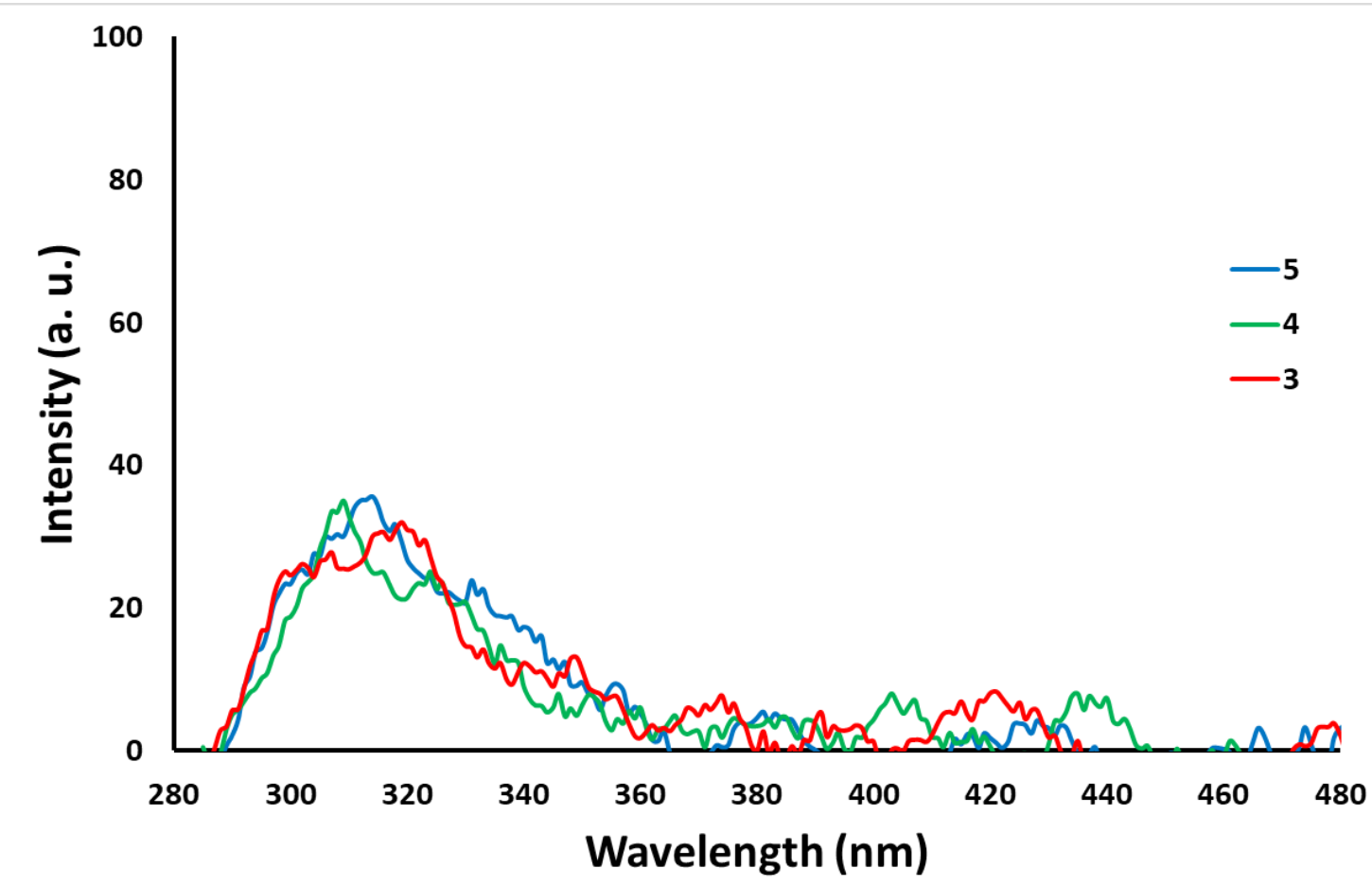

Figure 7: Fluorescence emission spectra of compounds 3-5 in THF. (Concentration: $1 \times 10^{-6} \mathrm{~mol} \mathrm{dm}^{-3} ; \lambda_{\mathrm{ex}}$ : $270 \mathrm{~nm})$.

It was determined that 2-naphthylthio cyclotriphosphazene derivatives showed weak fluorescence especially when compared to full naphthylamine substituted cyclotriphosphazene derivative. When the fluorescence properties in $1 \times 10^{-5} \mathrm{M}$ THF were examined, emission bands around $310 \mathrm{~nm}$ were observed again in all three compounds. But there have been changes in emission band strengths. Emission intensity was determined as 3>4>5 (Figure 8). The reason for the difference here may be self-quenching depending on the increase in concentration.

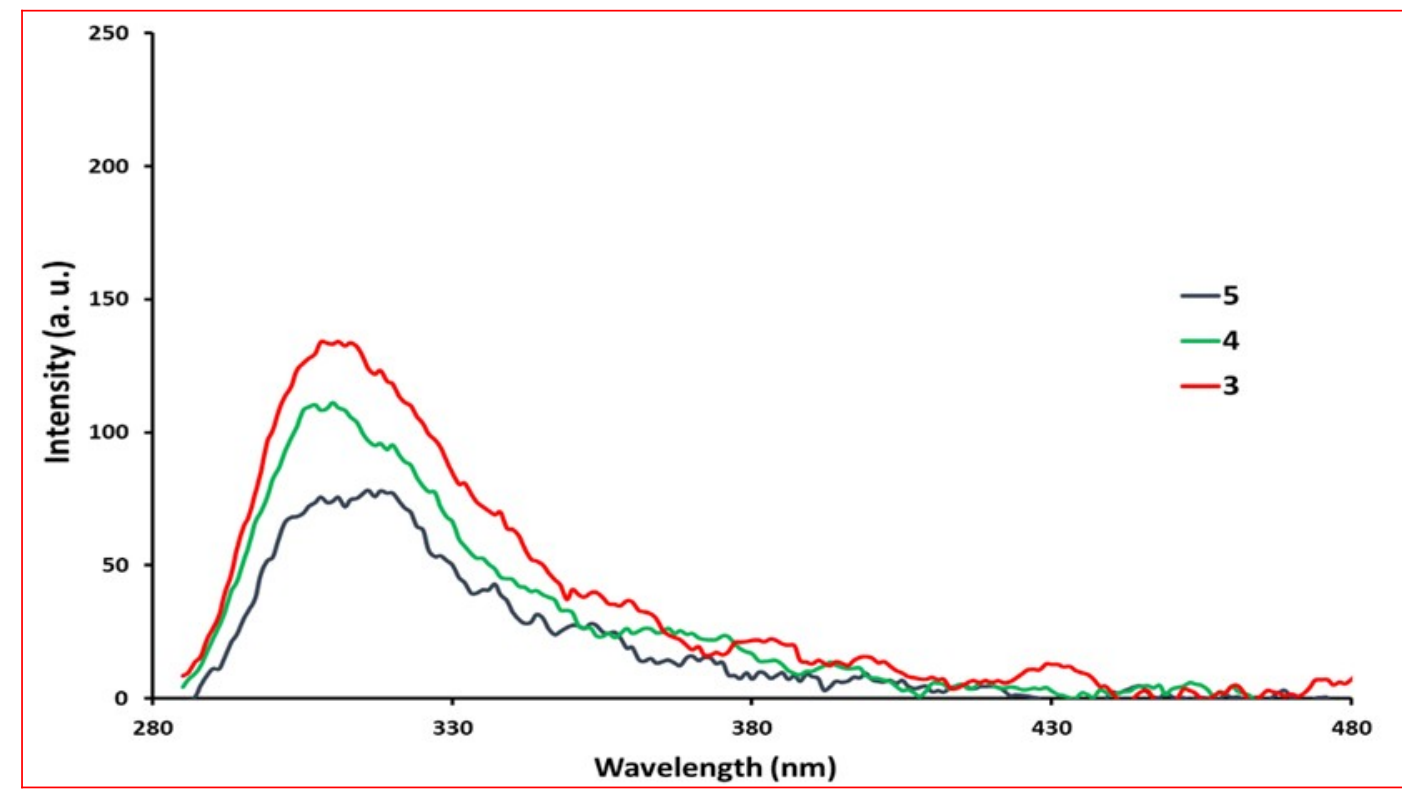

Figure 8: Fluorescence emission response of compounds 3-5 in THF solutions. (Concentration: $1 \times 10^{-5} \mathrm{~mol}$ $\left.\mathrm{dm}^{-3} ; \lambda \mathrm{ex}: 270 \mathrm{~nm}\right)$. 


\section{CONCLUSION}

In this study, three new cyclotriphosphazene derivatives bearing with 2-naphthylthio groups (35) were synthesized. Their structures have been elucidated using various analysis methods $\left({ }^{1} \mathrm{H},{ }^{31} \mathrm{P}\right.$ NMR, MALDI-TOF and elemental analysis). Moreover, the molecular structure of compound $\mathbf{3}$ was illuminated with single crystal X-Ray diffractometer. The crystal structure of bis geminal 1-naphthylthio cyclotriphosphazene, which is the binding isomer of each other and previously synthesized, and the crystal structure of compound $\mathbf{3}$ in this study were compared with previous work in the literature. While the naphthalene groups in compound $\mathbf{3}$ are parallel to the cyclotriphosphazene ring, in the 1-naphthylthio group, unlike this structure, the naphthalene groups diverged from each other and turned downward. Fluorescence spectral properties of 3-5 compounds were studied for the first time. It was determined that cyclotriphosphazenes containing 2-naphthylthio group gave fluorescence signal around $310 \mathrm{~nm}$. This study will provide a guide for future studies, because of the examination of fluorescence properties of 2-naphthylthio groups.

\section{Appendix A. Supplementary Data}

CCDC 2052687 contains the supplementary crystallographic data for compound $\mathbf{3}$. This data can be obtained free of charge via http://www.ccdc.cam.ac.uk/conts/retrieving.html, or from the Cambridge Crystallographic Data Centre, 12 Union Road, Cambridge CB2 1EZ, UK; fax: (+44) 1223-336-033; or e-mail: deposit@ccdc.cam.ac.uk

\section{REFERENCES}

1. Gleria M, Jaeger RD, editors. Applicative aspects of cyclophosphazenes. New York: Nova Science Publishers; 2004. 371 p.

2. Allcock HR. Chemistry and applications of polyphosphazenes [Internet]. Hoboken, N.J: WileyInterscience; 2003. 725 p. Available from: https://www.wiley.com/en-us/Chemistry+and+Appli cations+of+Polyphosphazenes-p-9780471443711

3. Bowers DJ, Wright BD, Scionti V, Schultz A, Panzner MJ, Twum EB, et al. Structure and Conformation of the Medium-Sized Chlorophosphazene Rings. Inorg Chem. 2014 Sep 2;53(17):8874-86.

4. Uslu A, Mutlu Balcı C, Yuksel F, Özcan E, Dural S, Beşli S. The investigation of thermosensitive properties of phosphazene derivatives bearing amino acid ester groups. J Mol Struct. 2017 May;1136:90-9.
5. Liu X, Breon JP, Chen C, Allcock HR. Substituent exchange reactions of trimeric and tetrameric aryloxycyclophosphazenes with sodium 2,2,2-trifluoroethoxide. Dalton Trans. 2012;41(7):2100-9.

6. Jiménez J, Callizo L, Serrano JL, Barberá J, Oriol L. Mixed-Substituent Cyclophosphazenes with Calamitic and Polycatenar Mesogens. Inorg Chem. 2017 Jul 17;56(14):7907-21.

7. Kumar D, Singh N, Keshav K, Elias AJ. RingClosing Metathesis Reactions of Terminal AlkeneDerived Cyclic Phosphazenes. Inorg Chem. 2011 Jan 3;50(1):250-60.

8. Mukundam V, Dhanunjayarao K, Mamidala $\mathrm{R}$, Venkatasubbaiah K. Synthesis, characterization and aggregation induced enhanced emission properties of tetraaryl pyrazole decorated cyclophosphazenes. J Mater Chem C. 2016;4(16):3523-30.

9. Allen CW, Brown DE, Worley SD. Synthesis and Spectroscopy of $\mathrm{N}_{3} \mathrm{P}_{3} \mathrm{X}_{5} \mathrm{OCHCH}_{2}(\mathrm{X}=\mathrm{Cl}, \mathrm{F}$, $\left.\mathrm{OCH}_{3}, \mathrm{OCH}_{2} \mathrm{CF}_{3}, \mathrm{~N}\left(\mathrm{CH}_{3}\right)_{2}\right)$ and $\mathrm{N}_{3} \mathrm{P}_{3} \mathrm{X}_{4}$ $\left(\mathrm{OCHCH}_{2}\right)_{2}\left(\mathrm{X}=\mathrm{Cl}, \mathrm{N}\left(\mathrm{CH}_{3}\right)_{2}\right)$. Correlations of Ultraviolet Photoelectron Spectroscopy and Nuclear Magnetic Resonance Data to Electronic and Geometrical Structure. Inorg Chem. 2000 Feb;39(4):810-4.

10. Ainscough EW, Brodie AM, Davidson RJ Moubaraki B, Murray KS, Otter CA, et al. Metal-Metal Communication in Copper(II)

Complexes of Cyclotetraphosphazene Ligands. Inorg Chem. 2008 Oct 20;47(20):9182-92.

11. Keshav K, Singh N, Elias AJ. Synthesis and Reactions of Ethynylferrocene-Derived Fluoro- and Chlorocyclotriphosphazenes. Inorg Chem. 2010 Jun $21 ; 49(12): 5753-65$.

12. Carriedo GA, García Alonso FJ, Gómez Elipe $P$, Brillas E, Labarta A, Juliá L. Macromolecular Polyradicals with Cyclic Triphosphazene as a Core. Spectral and Electrochemical Properties. J Org Chem. 2004 Jan;69(1):99-104

13. Liang W-J, Li Y-L, Zhao P-H, Zhao G-Z. Facile synthesis, spectroscopic characterization, and crystal structures of dioxybiphenyl bridged cyclotriphosphazenes. Polyhedron. 2017 Jun; 129:30-7

14. Zhu $X$, Liang $Y$, Zhang $D$, Wang $L, Y e ~ Y$, Zhao $Y$. Synthesis and Characterization of Side Group-Modified Cyclotetraphosphazene Derivatives. 
Phosphorus Sulfur Silicon Relat Elem. 2011 Jan $31 ; 186(2): 281-6$.

15. Okutan E, Çoşut B, Beyaz Kayıran S, Durmuş M, Kılıç A, Yeşilot $S$. Synthesis of a dendrimeric phenoxy-substituted cyclotetraphosphazene and its non-covalent interactions with multiwalled carbon nanotubes. Polyhedron. 2014 Jan;67:344-50.

16. Okumuş A, Elmas G, Cemaloğlu R, Aydın B, Binici $A$, Şimşek $H$, et al. Phosphorus-nitrogen compounds. Part 35. Syntheses, spectroscopic and electrochemical properties, and antituberculosis, antimicrobial and cytotoxic activities of monoferrocenyl-spirocyclotetraphosphazenes. New J Chem. 2016;40(6):5588-603.

17. Akbaş $\mathrm{H}$, Karadağ $A$, Destegül $A$, Çakırlar Ç, Yerli $Y$, Tekin KC, et al. Synthesis, and spectroscopic, thermal and dielectric properties of phosphazene based ionic liquids: OFET application and tribological behavior. New J Chem. 2019;43(5):2098-110.

18. Beşli S, Mutlu Balcı C, Doğan S, Allen CW. Regiochemical Control in the Substitution Reactions of Cyclotriphosphazene Derivatives with Secondary Amines. Inorg Chem. 2018 Oct;57(19):12066-77.

19. Yıldırım T, Şenkuytu E, Ergene E, Bilgin K, Uludağ Y, Çiftçi GY. Biological Activity of New Cyclophosphazene Derivatives Including Fluorenylidene-Bridged Cyclophosphazenes. ChemistrySelect. 2018 Sep 14;3(34):9933-9.

20. Ün İ, İbişoğlu H, Kılıç A, Ün ŞŞ, Yuksel F. Nucleophilic substitution reactions of adamantane derivatives with cyclophosphazenes. Inorganica Chim Acta. 2012 May;387:226-33.

21. Yenilmez Çiftçi G, Şenkuytu E, Durmuş M, Yuksel F, Kılıç A. Fluorenylidene bridged cyclotriphosphazenes: 'turn-off' fluorescence probe for $\mathrm{Cu} 2+$ and Fe3+ ions. Dalton Trans. 2013;42(41): 14916 .

22. Elmas (nee Egemen) G, Okumuş A, Kılıç Z, Hökelek T, Açık L, Dal H, et al. Phosphorus-Nitrogen Compounds. Part 24. Syntheses, Crystal Structures, Spectroscopic and Stereogenic Properties, Biological Activities, and DNA Interactions of Novel Spiroansa-spiro- and Ansa-spiro-ansacyclotetraphosphazenes. Inorg Chem. 2012 Dec 3;51(23):12841-56.

23. Yıldırım T, Bilgin K, Çiftçi GY, Eçik ET, Şenkuytu E, Uludağ $Y$, et al. Synthesis, cytotoxicity and apoptosis of cyclotriphosphazene compounds as anti-cancer agents. Eur J Med Chem. 2012 Jun;52:213-20.

24. Çiftçi GY, Eçik ET, Yıldırım T, Bilgin K, Şenkuytu E, Yuksel F, et al. Synthesis and characterization of new cyclotriphosphazene compounds. Tetrahedron. 2013 Feb;69(5):1454-61.

25. Davarcı D, Beşli S, Demirbas E. Synthesis of a series of triple-bridged cyclotriphosphazene hexaalkoxy derivatives and investigation of their structural and mesomorphic properties. Liq Cryst. 2013 May 1;40(5):624-31.

26. Bolink HJ, Santamaria SG, Sudhakar S, Zhen C, Sellinger A. Solution processable phosphorescent dendrimers based on cyclic phosphazenes for use in organic light emitting diodes (OLEDs). Chem Commun. 2008;(5):618-20.

27. Dell D, Fitzsimmons BW, Shaw RA. 752. Phosphorus-nitrogen compounds. Part XIII. Phenoxy- and p-bromophenoxychlorocyclotriphosphazatrienes. J Chem Soc. 1965;0(0):4070-3.

28. Schmutz JL, Allcock HR. Phosphorusnitrogen compounds. XXIII. Reaction of sodium 2,2,2-trifluoroethoxide with hexachlorocyclotriphosphazene. Inorg Chem. 1975 Oct; 14(10):2433-8.

29. Carter KR, Calichman M, Allen CW. Stereodirective Effects in Mixed Substituent Vinyloxycyclotriphosphazenes. Inorg Chem. 2009 Aug 3;48(15):7476-81.

30. Nataro C, Myer CN, Cleaver WM, Allen CW. Synthesis and characterization of ferrocenylalcohol derivatives of hexachlorocyclotriphosphazene. X-ray crystal structure of N3P3Cl5OCH2CH2C5H4FeCp. J Organomet Chem. 2001 Dec;637-639:284-90.

31. Coles SJ, Davies DB, Hursthouse MB, İbişoğlu $H$, Kılıç $A$, Shaw RA. 4,4,6,6-Tetrachloro-2[(2,4-dimethylphenyl)sulfanyl]- $N-[4-(2,2,4,4-$ tetrachloro-1,3,5,7,11-pentaaza- $2 \lambda^{5}, 4 \lambda^{5}, 6 \lambda^{5}$ triphosphaspiro[5.5] undeca-1,3,5-trien-7-yl)butyl]$1,3,5,2 \lambda{ }^{5}, 4 \lambda{ }^{5}, 6 \lambda^{5}$-triazatriphosphinin-2-amine.

Acta Crystallogr Sect E Struct Rep Online. 2007 Sep $15 ; 63(9)$ :03753-03753.

32. İbişoğlu H, Dal H, Hökelek T, Kılıç A, Ün İ, Vardı S. The reaction of thiophenoxide with aminosubstituted chloro-cyclotriphosphazenes.

Polyhedron. 2009 Sep;28(14):2863-70.

33. Carroll AP, Shaw RA. Phosphorus-nitrogen compounds. Part XXI. Alkylthio- and phenylthio- 
cyclotriphosphazatrienes. ] Chem Soc A. $1966 ; 0(0): 914-21$.

34. Jung O-S, Park SH, Lee Y-A, Cho Y, Kim KM, Lee $S$, et al. Unique Intramolecular Interaction in Cyclotriphosphazene Molecule. Synthesis, Structure, and Properties of 1,1-Bis(pyridyl-2-thio)-3,3,5,5tetrachlorocyclotriphosphazene. Inorg Chem. 1996 Jan;35(23):6899-901.

35. Allen CW. Regio- and stereochemical control in substitution reactions of cyclophosphazenes. Chem Rev. 1991 Mar;91(2):119-35.

36. Allcock HR. Recent advances in phosphazene (phosphonitrilic) chemistry. Chem Rev. 1972 Aug;72(4):315-56.

37. İbişoğlu H, Güzel AM. Syntheses and characterizations of cyclotriphosphazenes containing 1-naphthyl derivatives. Polyhedron. 2015 Nov; 100:139-45.

38. Yenilmez Çiftçi G, Şenkuytu E, Durmuş M, Yuksel F, Kılıç A. Structural and fluorescence properties of 2-naphthylamine substituted cyclotriphosphazenes. Inorganica Chim Acta. 2014 Nov;423:489-95.

39. Çoşut B, Yeşilot S. Synthesis, thermal and photophysical properties of naphthoxycyclotriphosphazenyl-substituted dendrimeric cyclic phosphazenes. Polyhedron. 2012 Mar;35(1):101-7.

40. Bruker AXS Inc. SADABS. Madison, WI, USA; 2005.

41. Bruker AXS Inc. APEX2, version 2014.1-1. Madison, WI, USA; 2014.

42. Sheldrick GM. A short history of SHELX. Acta Crystallogr A. 2008 Jan 1;64(1):112-22.

43. A.L.Spek. PLATON. Netherlands: Utrecht University, Padualaan 8, 3584 CH Utrecht;

44. Macrae CF, Bruno IJ, Chisholm JA, Edgington PR, McCabe P, Pidcock E, et al. Mercury CSD 2.0 - new features for the visualization and investigation of crystal structures. J Appl Crystallogr. 2008 Apr 1;41(2):466-70.

45. Brandenburg, K., Berndt, M. Diamond. Bonn, Germany: Crystal impact Gb R; 1999.

46. Çoşut B, Durmuş M, Kılıç A, Yeşilot S. Synthesis, thermal and photophysical properties of phenoxy-substituted dendrimeric cyclic phosphazenes. Inorganica Chim Acta. 2011 Jan;366(1):161-72. 


\title{
2-Naphthylsulfanyl Cyclotriphosphazene Derivatives: Synthesis,
} Characterization, Crystallographic and Fluorescence Properties

\section{Ceylan MUTLU BALCI ${ }^{1 *}$}

\begin{abstract}
${ }^{1}$ Department of Chemistry, Gebze Technical University, Gebze 41400, Kocaeli, Turkey Corresponding author e-mail: ceylanmutlu@gtu.edu.tr
\end{abstract}

\section{Supplementary Material}

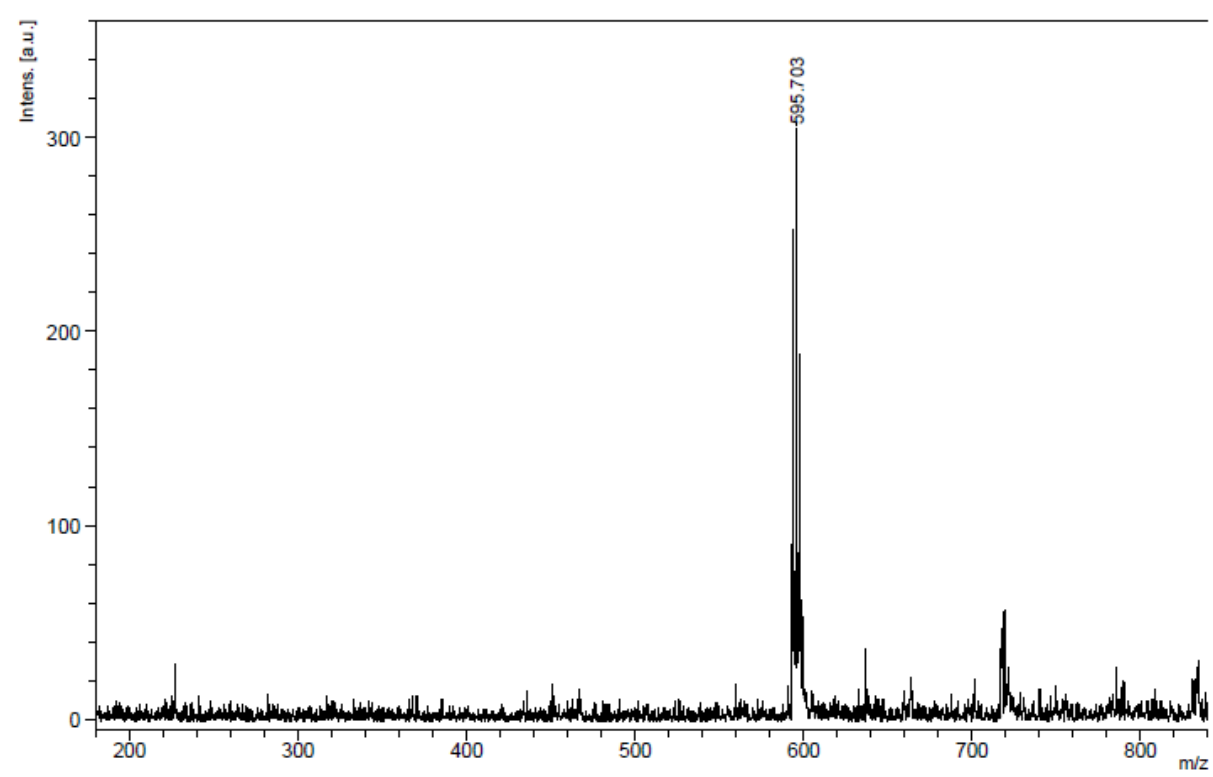

Figure S1. Mass spectrum (MALDI-TOF) of compound $\mathbf{3}$

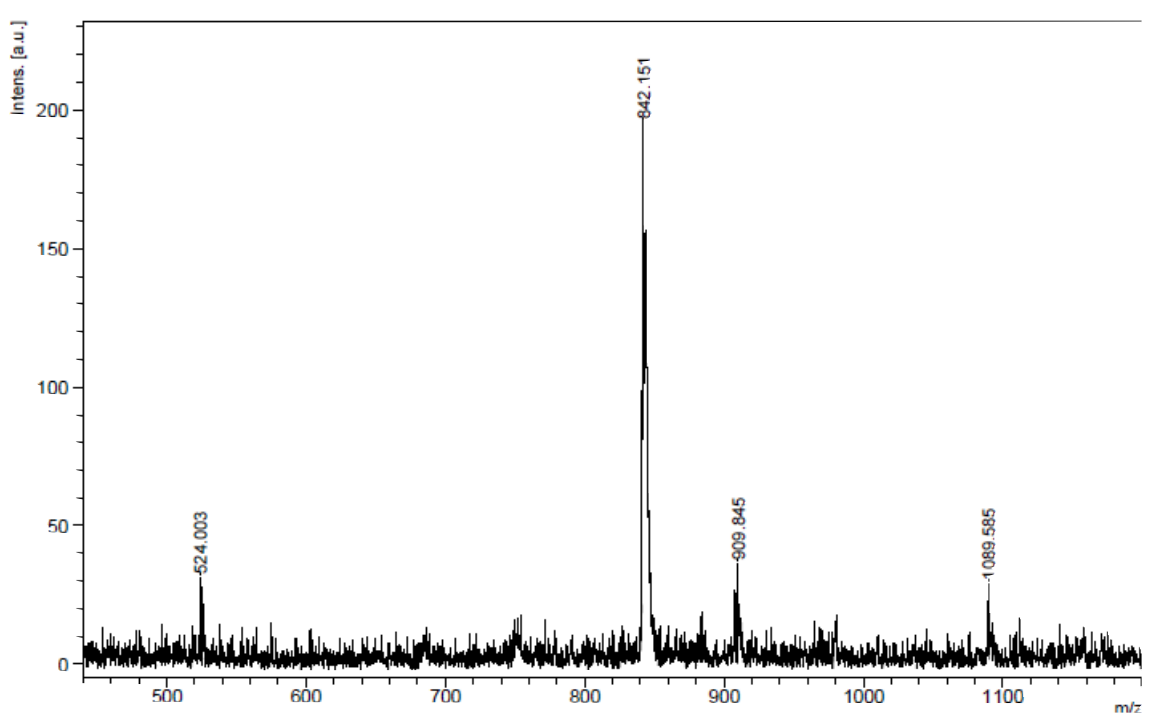

Figure S2. Mass spectrum (MALDI-TOF) of compound 4 


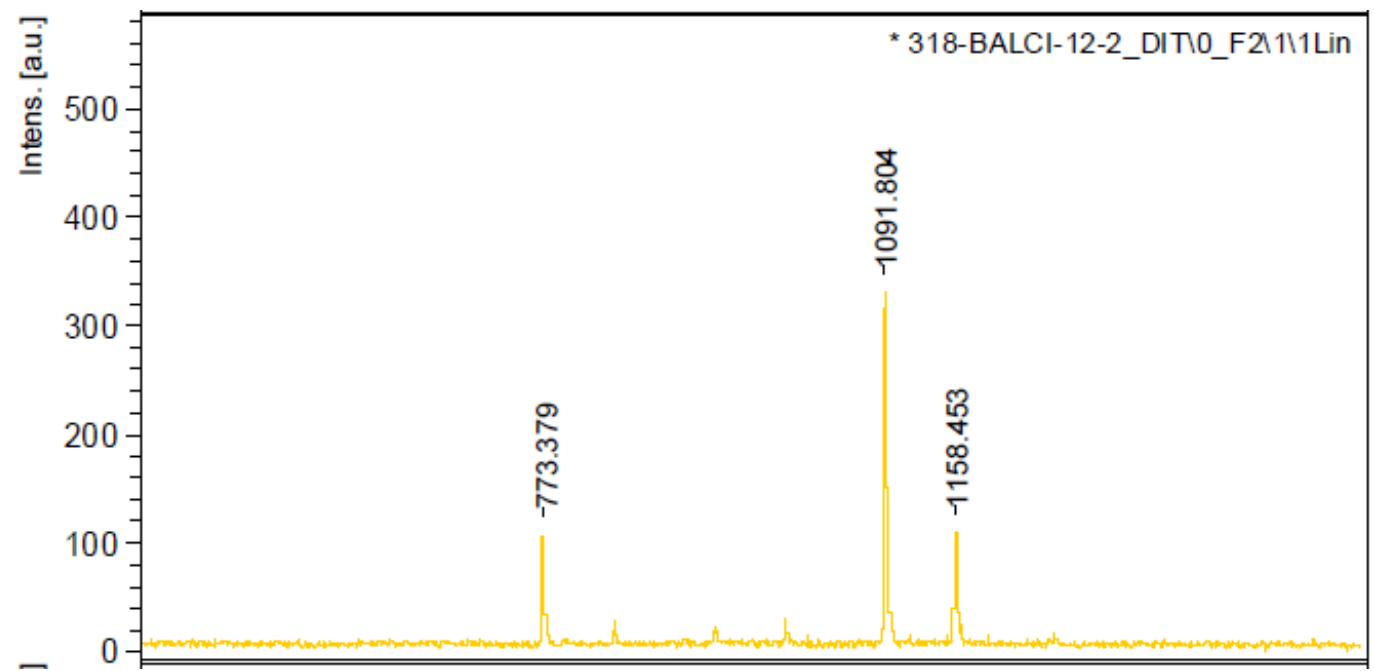

Figure S3. Mass spectrum (MALDI-TOF) of compound $\mathbf{5}$
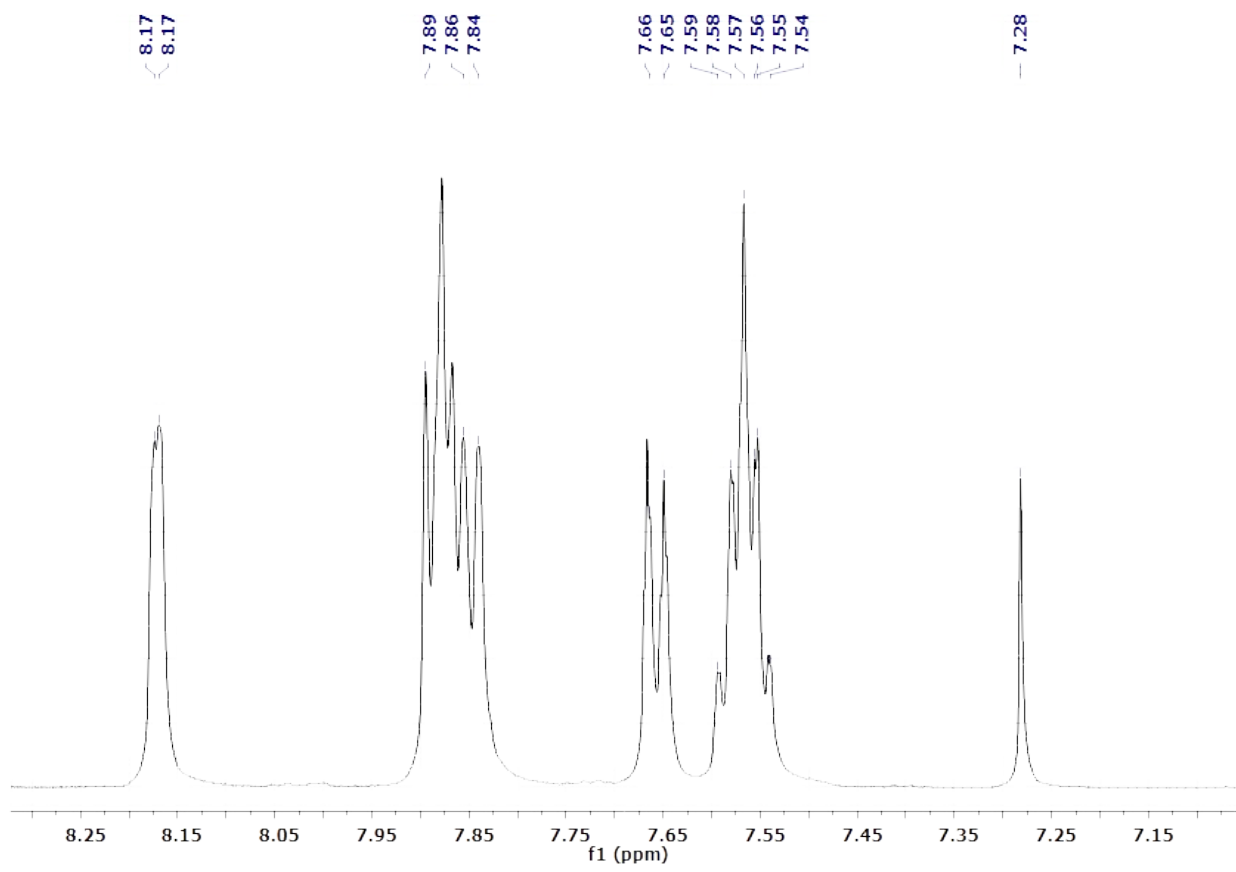

Figure S4. ${ }^{1} \mathrm{H}$ NMR spectrum of the compound 3. 


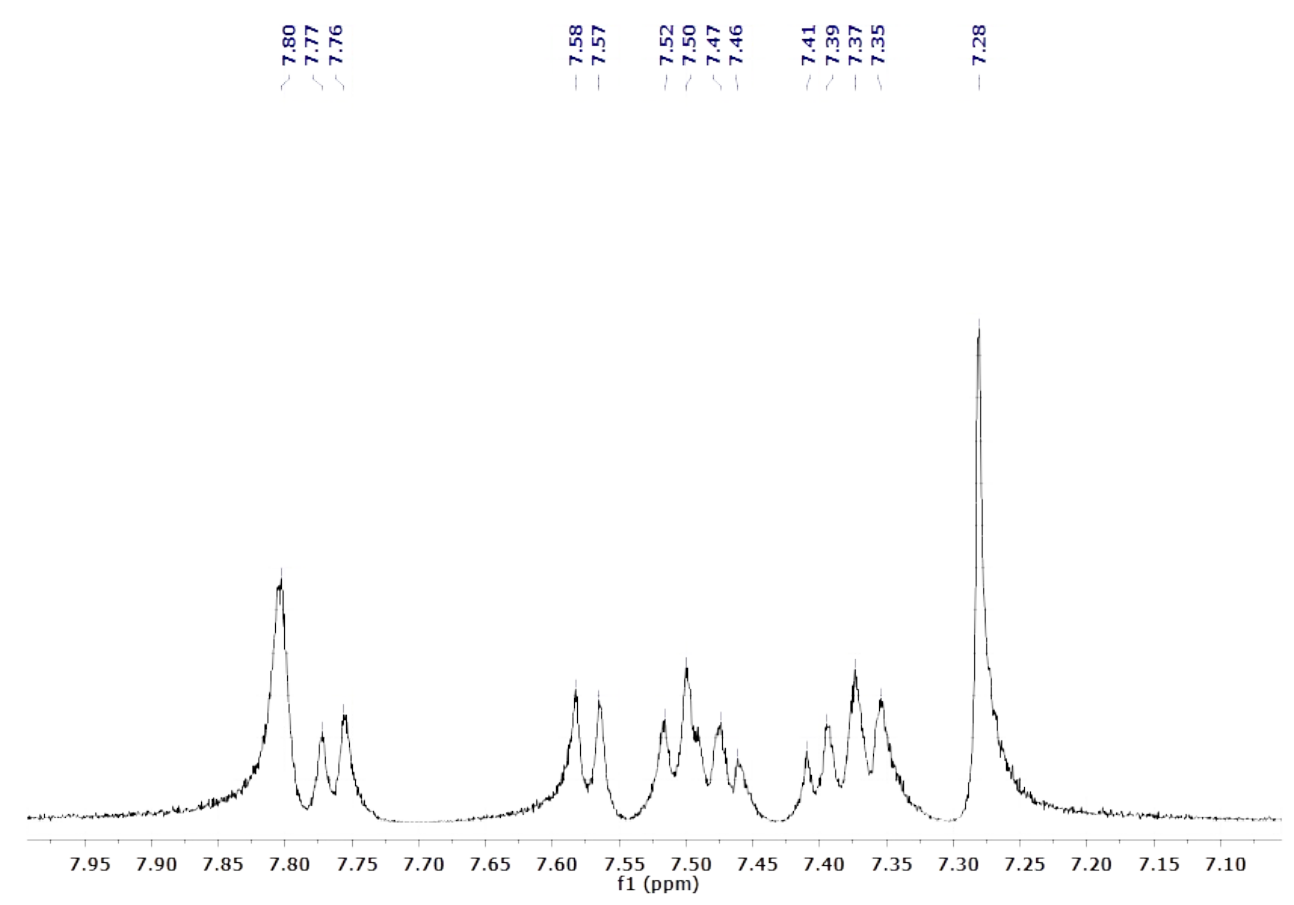

Figure S5. ${ }^{1} \mathrm{H}$ NMR spectrum of the compound 5. 
Mutlu Balcı C. JOTCSA. 2021; 8(2): 535-552. 